\title{
El diario Clarín y la cuestión de la "lucha antisubversiva" en el golpe militar de 1976 en la Argentina ${ }^{1}$
}

Marcelo Borrelli*

Resumen: Este artículo se propone analizar la argumentación editorial del matutino argentino Clarín en relación a su defensa de la "lucha antisubversiva" durante los últimos meses del gobierno peronista de Isabel Perón en 1975 y los primeros de 1976, luego de concretado el golpe de Estado del 24 de marzo de ese año. En particular, se indagará en sus posiciones editoriales desde octubre de 1975, cuando el gobierno peronista decretó la intervención de las Fuerzas Armadas en la "lucha antisubversiva" a todo el territorio nacional, hasta septiembre de 1976 al cumplirse el primer semestre del golpe, momento en que el matutino realizará un balance sobre el nuevo gobierno militar.

Palabras clave: Dictadura militar argentina. Golpe de estado de 1976. Diario Clarín. Prensa argentina. "Lucha antisubversiva".

* Marcelo Borrelli es Doctor en Ciencias Sociales (UBA), Magíster en Comunicación y Cultura (UBA) y Licenciado en Ciencias de la Comunicación (UBA). Es Investigador asistente del CONICET, institución de la que fue becario. Es profesor de la carrera de Ciencias de la Comunicación de la Facultad de Ciencias Sociales (UBA) y ha integrado como investigador varios proyectos UBACyT y PICT. Coordina cursos de posgrado en modalidad virtual sobre historia reciente y ciudadanía política en CAICYT-CONICET. Es autor de los libros Voces y silencios. La prensa argentina y la dictadura militar (EUDEBA, 2011) (co-coordinador), "El diario de Massera". Historia y política editorial de Convicción: la prensa del "Proceso" (KOYATUN, 2008) y El fundamentalismo islámico (coautor, Dastin, 2006) y de numerosos artículos en revistas y congresos sobre la historia de la prensa durante los años setenta. También ha investigado sobre la enseñanza de la historia reciente y las Ciencias Sociales. E-mail: marcebor@gmail.com 
El diario Clarín y la cuestión de la "lucha antisubversiva" en el golpe militar...

\section{Introducción}

Este artículo se propone analizar la argumentación editorial del matutino Clarín en relación a su defensa de la "lucha antisubversiva" durante los últimos meses del gobierno peronista de Isabel Perón en 1975 y los primeros de 1976, luego de concretado el golpe

de Estado del 24 de marzo de ese año. En particular, se indagará en sus posiciones desde octubre de 1975, cuando el gobierno peronista decretó la intervención de las Fuerzas Armadas en la "lucha antisubversiva" a todo el territorio nacional, hasta septiembre de 1976 al cumplirse el primer semestre del golpe, momento en que el matutino realizará un balance sobre el nuevo gobierno militar.

El periodo elegido nos permitirá indagar en las continuidades, variaciones y eventuales rupturas del discurso editorial del matutino en relación a la cuestión de la "lucha antisubversiva", teniendo en cuenta el cambio de gobierno acaecido por el golpe de Estado. A la vez, se intentará observar su evaluación del contexto de violencia política previo al golpe, donde ya existían prácticas represivas estatales y paraestatales clandestinas y criminales - aunque cualitativamente menores en relación a los años posteriores al golpe de 1976 -, y frente a la radicalización posterior al 24 de marzo, haciendo hincapié en cómo este proceso influyó en su política editorial en torno a la "cuestión subversiva".

La importancia del estudio de esta problemática se pone de relieve al tener en cuenta que durante el segundo semestre de 1975 la situación política y económica de la Argentina estaba evidenciando una creciente desestabilización, que incluyó un incremento de las acciones políticas violentas de parte de las organizaciones políticas-armadas de izquierda y las bandas paraestatales de derecha, así como la ampliación de la participación represiva del Estado nacional a través de las Fuerzas Armadas. En este contexto, percibido por muchos ciudadanos como "caótico", aspecto que también era impulsado por aquellos sectores de la vida nacional interesados en que el gobierno peronista fuera derrocado por las fuerzas militares, el rol de la prensa argentina se tornó de máxima relevancia para convalidar o desestimar las corrientes de opinión que apoyaban una mayor desestabilización de la situación política. 
En ese sentido, es que un estudio sobre uno de los principales periódicos de circulación nacional del periodo se vuelve imprescindible para comprender el contexto que rodeó al golpe de Estado del 24 de marzo de 1976, como también los argumentos que legitimaron una profundización de la represión hacia los sectores políticos de la izquierda radical y peronista más combativos.

\section{Aspectos teóricos}

El trabajo se inscribe en su aspecto teórico y metodológico dentro de la tradición de análisis crítico del discurso (VAN DIJK, 1990), entendida en amplio sentido como una sociosemiótica que se orienta a analizar las prácticas sociales de producción y reconocimiento de significados en una comunidad determinada, y "las estrategias de manipulación, legitimación, creación de consenso y otros mecanismos discursivos que influyen en el pensamiento de las personas, a través de los medios" (KORNBLIT, 2004, p. 118). En este caso, el artículo se sitúa en el análisis discursivo de una publicación periódica, teniendo en cuenta sus condiciones de producción (VERÓN, 1987). Al entender a las condiciones de producción, como "un determinado contexto político, económico y social” (PÊCHEUX, 1978, p. 38) se deberá establecer las condiciones históricas y sociales en las que la enunciación del matutino Clarín fue producida (VOLOSHINOV, 1976). De allí que este artículo se proponga analizar y vincular los medios de prensa con una trama histórica, social y cultural determinada. Sobre esta base se comprende la posibilidad que el análisis de las publicaciones periódicas y sus posicionamientos ideológicos ofrecen para indagar el entrecruzamiento entre la historia política y la historia de las ideas. Desde esta perspectiva, las publicaciones no son meros soportes de ideologías que estarían por "detrás" de ellas, sino vehículos activos destinados a la conformación de espacios sociales, la construcción de públicos, la legitimación de corrientes de opinión, la influencia concreta en las decisiones políticas y otras de interés público y amplia incidencia social. 
El diario Clarín y la cuestión de la "lucha antisubversiva" en el golpe militar...

Por último, estudiaremos al espacio del editorial en tanto es el género discursivo de opinión e interpretación donde se condensa la opinión institucional de un medio de prensa, ya sea al expresar el punto de vista personal del director o de la empresa editora (CASTELLI, 1991, p. 193). Ese espacio será analizado tomando el esquema de Raúl Rivadeneira Prada sistematizado por Castelli (1991) que identifica diversos tonos o estilos característicos de los editoriales según su contenido, la actitud adoptada en su tratamiento y las circunstancias políticas y sociales bajo las cuales se inscriben. Por último, junto con Borrat (1989), entendemos al diario como un actor político que debe ser analizado teniendo en cuenta su capacidad de influir en la toma de decisiones colectivas; y, en esta línea, se propone que la gran prensa argentina tuvo un papel clave en la conformación de corrientes de opinión que legitimaron el golpe militar de 1976 y la ampliación de la intervención represiva de las Fuerzas Armadas Argentinas.

\section{El diario Clarín hacia 1976}

Clarín lanzó su primer número al público el 28 de agosto de 1945. Su fundador fue Roberto J. Noble, quien dirigió el diario hasta el día de su fallecimiento, el 12 de enero de 1969. Luego su esposa, Ernestina Herrera de Noble, se hizo cargo de la dirección del diario, la cual ha ejercido hasta la actualidad. Clarín tuvo una carrera ascendente desde su primer número y hacia fines de los años '60 ya se había constituido en uno de los primeros diarios en el ranking de ventas nacionales ${ }^{2}$. También se había posicionado como un referente clave de la clase media de los principales centros urbanos de la Argentina, en particular de Buenos Aires.

Hacia finales de la década del '50, y hasta inicios de la década del '80, Clarín abrazó el ideario político del desarrollismo argentino encabezado por el dirigente Rogelio Frigerio y el ex presidente Arturo Frondizi (1958-1962). Hacia 1970 esta vinculación se concretará en una alianza ideológica, política y financiera con el partido que aglutinaba al pensamiento desarrollista nacional, el Movimiento de Integración y Desarrollo (MID). El vínculo se 
expresó en su pensamiento editorial y en la participación de hombres del desarrollismo en Clarín, quienes trabajaron en la redacción del diario ejerciendo un verdadero "control ideológico" de su línea editorial y sobre las notas sensibles en relación a la política y a la economía (BORRELLI, 2010a).

En una muy breve referencia sobre el ideario desarrollista, debe apuntarse que para el desarrollismo la economía era la base de la cual dependían todos los demás niveles de la vida social argentina. Sin dar el "gran salto" del subdesarrollo hacia el desarrollo que refundaría a la sociedad argentina no podrían resolverse los acuciantes problemas nacionales. La demanda era planteada en términos drásticos, en tanto el país debía regenerarse a sí mismo a través de la "solución desarrollista": afianzar la sustitución de importaciones, avanzar en la tecnificación del campo y en la integración agroindustrial, integrar productivamente el país, modernizar la producción energética, consolidar el capital interno y estimular la llegada del capital externo, impulsar la inversión y las "industrias de base" - siderurgia, petroquímica, papelera, etc. - y afianzar la alianza de clases entre capital y trabajo para el progreso y la grandeza nacional, entre sus propuestas más relevantes (ACUÑA, 1984; NOSIGLIA, 1983).

\section{Clarín en la antesala del golpe militar: represión legal para refundar la Nación y desarrollo económico para asegurar la paz.}

Desde el intento frustrado del gobierno de Isabel Perón de plasmar un plan económico ortodoxo conocido como "Rodrigazo", en junio de $1975^{3}$, y hasta el golpe de Estado de 1976, la línea editorial del diario tendió a ser una caja de resonancia de las críticas negativas que el MID le destinó al gobierno peronista en su último tramo (BORRELLI, 2008) ${ }^{4}$. Desde mediados de $1975 \mathrm{el}$ gobierno peronista sufrió un vertiginoso proceso de licuación de poder, flanqueado por la agudización de la violencia política, los problemas económicos, los planes militares para desembarcar en 
El diario Clarín y la cuestión de la "lucha antisubversiva" en el golpe militar...

el poder, la militarización de la política, las peleas hacia dentro del peronismo y la pérdida de legitimidad del accionar presidencial, entre otras variables desestabilizadoras (DE RIZ, 1986; ITZCOVITZ, 1985; MACEYRA, 1983; NOVARO y PALERMO, 2003).

En ese contexto de desmoronamiento del poder gubernamental y de ajada institucionalidad democrática, los editoriales de Clarín advirtieron en un estilo crecientemente admonitorio ${ }^{5}$ sobre el incorrecto rumbo que había tomado el proceso abierto en $1973^{6}$, la fatigante crisis económica, "moral" y política y el cada vez más necesario salto hacia el "desarrollo". La demanda era planteada en términos refundacionales, en tanto para el matutino el país debía regenerarse a sí mismo a través de la puesta en marcha de lo que hemos denominado como la "solución desarrollista".

En un contexto sumamente inestable, la situación política nacional se inclinó un poco más hacia su total militarización cuando el 5 de octubre de 1975 la agrupación peronista Montoneros realizó un fallido intento de copamiento del Regimiento $29^{\circ}$ de Infantería de Monte en Formosa que concitó el rechazo de la clase política y otros sectores de la dirigencia nacional ${ }^{7}$. Era el primer ataque de tal envergadura que Montoneros dirigía contra un objetivo del Ejército y terminó de cohesionar internamente a esa fuerza para reprimir a la organización de la izquierda peronista, legitimó a la fracción antiperonista del arma, que era partidaria de la represión ilegal, y relegó definitivamente a los sectores más nacionalistas. Además, fue una excusa política ideal para convalidar legalmente la extensión de la represión encabezada por las Fuerzas Armadas a todo el país (hasta ese momento la acción represiva del Ejército estaba acotada desde febrero de 1975 a la provincia de Tucumán, donde combatía con métodos legales e ilegales a las fuerzas del Ejército Revolucionario del Pueblo, de extracción trotskista).

En efecto, el 6 de octubre el gobierno creó por decreto 2770 el Consejo de Seguridad Interna que dependería de la presidenta y estaría integrado por los ocho ministros del gabinete y los tres comandantes en jefe de las Fuerzas Armadas. Tendría como objetivo conducir políticamente la "lucha contra la subversión" y, en los hechos, ampliaba a todo el país la intervención represiva de las Fuerzas Armadas ${ }^{8}$. Luego, el 8 de octubre, el presidente provisional 
Italo Lúder, a cargo interinamente del Poder Ejecutivo por una licencia por cuestiones de salud de Isabel Perón, firmaría el decreto conocido como de "aniquilamiento" 2772 por el cual "las Fuerzas Armadas, bajo el comando superior del presidente de la Nación, que será ejercido a través del Consejo de Defensa, procederán a ejecutar las operaciones militares y de seguridad que sean necesarias a los efectos de aniquilar el accionar de los elementos subversivos en todo el territorio del país" (Clarín, 9/10/1975, p. 17)9. El manto de legalidad que ofrecían los decretos, y la autonomía en la represión que otorgaba el poder político a las Fuerzas Armadas, fue una exigencia de los comandantes; a cambio se comprometían a no derrocar al gobierno. En los hechos, los decretos implicaron el predominio en la represión de las fuerzas militares y policiales desplazando a la Alianza Anticomunista Argentina, más conocida como "Triple A", que prácticamente desaparecerá en el primer trimestre de 1976 (GARCÍA, 1995, p. 437-42) y cuyos cuadros más tarde serán integrados en los Grupos de Tareas que operarán clandestinamente durante la dictadura militar ${ }^{10}$.

$\mathrm{El}$ ataque en Formosa despertó la agria condena del matutino, en un editorial a cuatro columnas que abarcaba casi todo la página, formato solo reservado por el diario para situaciones excepcionales o graves. Allí lo calificó como una "agresión insensata y alevosa" que reflejaba la negación "terminante y final" de cualquier tentativa de "convivencia" y "conciliación" (Clarín, 9/10/1975). La gravedad de lo sucedido para el diario se comprende si se tiene en cuenta que pocos días antes, en un editorial de igual dimensión, se había preguntado desde su título "¿A dónde se está llevando al país?" (Clarín, 5/10/1975), y por primera vez desde el "Rodrigazo" mencionaba el tema del golpe, en relación a los rumores que corrían al respecto.

La intervención militar decretada por el presidente provisional Lúder era aprobada en forma contundente. El tono de cruzada palingenésica recorría todo el editorial. No era solo la violencia que con su "nihilismo paralizante" atentaba contra la paz, sino también que en otros aspectos de la vida nacional se verificaban conductas y hechos que destruían la "entereza moral de nuestro pueblo". En esta línea, recurría a la "voz rectora" de la Iglesia para ofrecer su 
El diario Clarín y la cuestión de la "lucha antisubversiva" en el golpe militar...

visión sobre la situación nacional en relación a la "violencia" y citaba las palabras del arzobispo de la ciudad de Rosario (provincia de Santa $\mathrm{Fe}$ ) que el 7 de octubre, en un discurso realizado también en clave de cruzada, había afirmado que en la Argentina se había acabado el orden, la paz y la tranquilidad y había llegado "el momento de alertar sobre otro peligro de consecuencias igualmente funestas: si en nuestra patria no se detiene la ola de inmoralidad creciente, el país no solo no saldrá de las crisis que lo aqueja sino que entrará muy pronto en una decadencia que lo llevará al derrumbe como nación" (Clarín, 9/10/1975).

Clarín compartía la advertencia del obispo sobre el "relajamiento de los escrúpulos morales" que se observaba en el pueblo. En consonancia, el editorial estaba cargado de referencias de fuerte contenido ético y moral (la palabra moral era mencionada en cinco oportunidades y se utilizaban otras definiciones vinculadas como "decaimiento moral" o "quiebra de la ética"). Por otra parte, para Clarín, cualquiera fuera el intento de explicar la violencia, que era parte integrante de la quiebra ética, no podía obviarse que su causa "más profunda" consistía en "el grave desquicio" del orden económico nacional. De allí que la extensión de la represión, aunque necesaria y justificada, por sí sola no resolvería la cuestión:

No caben ya dudas de que nuestro país se encuentra hoy en guerra. Tampoco deben existir vacilaciones en cuanto a que la empresa armada y violenta de la subversión debe ser combatida con las armas que la República ha depositado en sus fuerzas militares. Pero en este conflicto global, que abarca todos los sectores de la vida nacional, existen otros teatros de operaciones donde el combate debe ser llevado sin tregua.

[...] es imperativo reconstruir los cimientos materiales de la Nación y sobre ellos edificar el orden económico que dé satisfacción a las apetencias de sus habitantes. Resulta así vital recuperar el lamentable tiempo perdido, rectificar el rumbo equivocado y reunir al país en torno del objetivo de todas las generaciones argentinas: hacerlo grande y próspero. 
[...] No reconocerlo llevará a agotar los esfuerzos en una interminable represión que se añadirá como una más a la lista de las frustraciones argentinas. Porque como lo decía el papa Paulo VI [...] "el desarrollo es el nuevo nombre de la paz” (Clarín, 9/10/1975).

Apelando nuevamente a la palabra de la Iglesia, en este caso en la cita de la encíclica "Populorum Progressio" del Papa Paulo VI", realizaba una interpretación que se enraizaba en su visión economicista y que tendía a simplificar las causas de la violencia política de las organizaciones político-armadas de izquierda. La represión dentro de una "guerra" estaba justificada, pero al estar desconectada de una política global que atacara las causas económicas del fenómeno "subversivo" terminaría condenada al fracaso. Por otra parte, el editorial, cargado de referencias "éticas" y "morales", no mencionaba tales condicionamientos a la hora de avalar la represión de las Fuerzas Armadas. Su moderada objeción, o la expresión de ciertas reservas sobre la "solución represiva", se vinculaban con criterios pragmáticos, por los cuales no tendría finalidad alguna reprimir sino se encaraba como parte de un plan integral que eliminara las causas que daban pábulo a la "subversión". Estas, en su visión, desaparecerían por la propia fuerza del progreso al hacer grande y próspero al país a través del desarrollo. Para Clarín, "las verdaderas armas de la paz" - así se titulaba el editorial - eran las del desarrollo ${ }^{12}$.

A propósito de cómo debía encararse la "lucha antisubversiva", es interesante analizar la proposición del matutino expresada hacia fines de noviembre de 1975. En ese momento, las Fuerzas Armadas ya se encontraban operando en todo el país en cumplimiento de los decretos de octubre, y la Cámara de Diputados acababa de aprobar un proyecto de Ley de Defensa Nacional enviado por el Ejecutivo en el que se había "adecuado" ese instrumento para complementar la cobertura legal en la lucha contra la guerrilla. El proyecto de Ley era una concesión más del gobierno nacional a las Fuerzas Armadas: entre sus aspectos más importantes ubicaba a los "delitos subversivos" bajo juzgamiento de tribunales militares que quedaban facultados para aplicar la pena de muerte prevista en el Código de Justicia Militar ${ }^{13}$. Clarín (22/11/1975) aprobó la 
El diario Clarín y la cuestión de la "lucha antisubversiva" en el golpe militar...

modificación del marco legal frente a la "necesidad de erradicar las actividades subversivas", porque las previsiones del sistema legal en tiempos "normales" se habían visto desbordadas por la acción guerrillera. Declaraba que era imposible: "desconocer que la naturaleza de esta actividad [...] hace que la amenaza se asimile a una virtual declaración de guerra y que frente a ello no quede otra alternativa que el combate en cada uno de los frentes en que quede planteada la agresión".

En efecto, la hipótesis de una "guerra", que años después argumentarían las Fuerzas Armadas como justificación para su plan represivo, no era exclusiva de los militares. Como señala Vezzetti (2002, p. 58), hacia mediados de los años '70 “el fantasma de la guerra fundaba la política" y el marco de sentido que proveía la noción de "guerra" era atizado tanto por la derecha como por la izquierda política (y quienes estaban involucrados en la lucha armada sin duda se sentían parte de una "guerra"). De la misma manera que Clarín lo expresaba, otros sectores - principalmente las Fuerzas Armadas, y también los partidos políticos, la Iglesia, la guerrilla, el propio gobierno y diversos sectores civiles - definían la situación de violencia política con el concepto de "guerra", al que utilizaban según sus propios intereses sectoriales ${ }^{14}$. De todas formas, el matutino aclaraba que estar en guerra no justificaba implementar metodologías represivas fuera de la ley:

La necesidad de dar a la lucha antisubversiva un respaldo legal es indispensable además para que no se incurra en la tentación de ejercitar la represión fuera de las leyes. Los implementos de combate no deben salir nunca de manos del Estado, al que le corresponde el monopolio de la fuerza, único modo en que ésta puede aplicarse de manera responsable, es decir, con titulares concretos y pasibles de rendir cuentas (Clarín, 22/11/1975).

Clarín refrendaba de esta manera su participación en el bloque civil que pedía una represión "ordenada" y "legal", pero dura y efectiva. Esta visión se alineaba con la opinión de sectores civiles que planteaban que la única forma de terminar tanto con la violencia 
guerrillera como con la represión paramilitar de "bandas de ultraderecha" era poniéndola en las manos "legales" de las Fuerzas Armadas. Así, se terminaría con la "anarquía" y se pondría fin a la deriva violenta a través de una fuerza perteneciente al propio Estado. De todas maneras, no puede dejar de remarcarse, en el caso de Clarín, la contradicción - o al menos la convivencia no armoniosa - entre esta advertencia "legalista" y sus llamados a soluciones drásticas utilizando metáforas bélicas. Y además debe advertirse sobre los posibles efectos legitimadores que estas demandas pudieron haber tenido para los planes represivos dentro de un contexto donde ya las Fuerzas Armadas - a quienes se les encomendaba la represión "legal" - llevaban adelante procedimientos ilegales, aunque sin la extensión posterior del terrorismo de Estado.

Mientras se iniciaban los conciliábulos golpistas, las Fuerzas Armadas expresaban en público su "preocupación" por la gravedad de la crisis y se mostraban "prescindentes" de los avatares políticos. Desde la firma de los decretos de "aniquilamiento" lideraban abiertamente la lucha contra la guerrilla con total autonomía del poder político y los poderes Ejecutivo, Parlamentario y Judicial ${ }^{15}$. Y el 23 de octubre, en la Conferencia de Ejércitos Americanos realizada en Montevideo, el entonces jefe del Ejército, Jorge Rafael Videla, adelantaba sin miramientos la filosofía de la política de exterminio que se implementaría poco tiempo después: "En la Argentina deberán morir todas las personas necesarias para lograr la paz del país", sentenciaba. La militarización de la política continuaba sigilosa, pero constante.

El último mes del agitado año 1975 se iniciará - y finalizará con el recrudecimiento de la violencia política. Durante los primeros seis días al menos 34 personas fueron asesinadas por motivos políticos (ANDERSEN, 2000, p. 197) ${ }^{16}$. En un operativo comando, Montoneros asesinó al general Cáceres Monié y a su esposa, acción que intensificó las declaraciones militares en tono de cruzada que, cada vez con mayores bríos y menos circunloquios, enfatizaban la necesidad de un cambio drástico. Ante la espectacularidad de los recientes atentados, las Fuerzas Armadas se presentaban como víctimas pasivas de las "subversión apátrida", presentaban como "lógica" su respuesta a la agresión y se ubicaban implícitamente como el único actor con soluciones definitivas para la "crisis nacional". 
El diario Clarín y la cuestión de la "lucha antisubversiva" en el golpe militar...

Clarín se pronunció gravemente en repudio del asesinato de Cáceres Monié, y también sobre el de 9 jóvenes militantes que aparecieron asesinados en Córdoba (Clarín, 6/12/1975). Ante el recrudecimiento de la violencia, el matutino hizo principal hincapié en su aspecto "irracional", en el "decaimiento" de la moral y en la necesidad del "cultivo de las virtudes éticas", y demandó, sin un destinatario específico, una "saludable reacción" y al Estado en particular que encabece el "proceso regenerador" que imponía la situación (Clarín, 6/12/1975). Un aval al disciplinamiento social de jaez autoritario, a las veleidades refundacionales que sin duda, junto con la voz de otros importantes actores sociales, otorgaban mayor legitimidad a una intervención política ejemplificadora.

Hacia fines de enero Clarín elogió por primera vez en forma abierta a Jorge Videla, aunque no lo mencionó por su apellido, sino por su función como jefe del Ejército (Clarín, 25/1/1976). Era también la primera vez, desde el "Rodrigazo", que realizaba una apreciación de este tipo sobre un jefe militar. El motivo residía en que Videla había mencionado que la "subversión" no era solo un problema militar, sino "global" en tanto abarcaba otros órdenes como el económico, el social y el político y además tenía un "matiz" militar. El jefe del Ejército había confirmado que la lucha militar estaba controlada, pero que la cuestión no se agotaba allí ya que había que seguir luchando en esos otros campos de la vida nacional. El matutino calificaba su respuesta como "una clara definición", "didáctica", "depurada" y en "ascético estilo" (Clarín, 25/1/1976). Al comentarla se mostraba particularmente satisfecho porque señalaba que no era suficiente la "victoria militar" y que la violencia se realimentaría si no se daban soluciones a los problemas nacionales que "exceden naturalmente al orden castrense". La declaración indicaba la obligación de "erradicar las causas que le proporcionan [a la "subversión"] un medio propicio para desenvolverse más allá de cuanto hay de delictivo en su accionar". Porque sin la concurrencia de esos factores, la "subversión" carecería del "efecto multiplicador" que había demostrado en los últimos años y se extinguiría o quedaría aislada "por las defensas naturales de un cuerpo social, política, moral y económicamente sano" ${ }^{17}$. Evidentemente, para Clarín en esa coyuntura la sociedad 
no ostentaba tales defensas, fruto de su anquilosamiento económico y derrumbe ético. Por último, luego de elogiar la "reflexión en voz alta" de Videla el editorial finalizaba:

El país está urgido de soluciones de fondo. El mal que lo afecta se ha agravado, como que está amenazado de desintegración. Para salir de este riesgo, que se genera en el estancamiento económico, en un mundo que avanza, es necesario consolidar al Estado nacional, proceder con energía a remover las causas del atraso. La vieja estructura y los intereses que luchan por mantenerla traban el crecimiento armónico de la economía, base cierta de la armonía social y de la paz interior (Clarín, 25/1/1976).

La complementación entre el elogio al jefe del Ejército, en un tono abiertamente apologético ${ }^{18}$, y la necesidad de las "soluciones de fondo" aparecían planteadas en una sugerente línea de causalidad implícita. También se destacaba la contraposición entre el elogio a Videla y los términos cada vez más drásticos con los que Clarín hacía referencia a la situación nacional y al oficialismo en especial.

La última semana previa al golpe de Estado fue particularmente vertiginosa. Todas las variables desestabilizadoras se aceleraron: el recrudecimiento de la violencia política, la atonía gubernamental y el deterioro económico. A partir de la segunda quincena de marzo el tono de los editoriales de Clarín se tornó aún más dramático, destacándose su tono catastrofista, pero también predictivo ${ }^{19}$ en relación a los sucesos cuya inminencia se predecía. Remarcó los errores del gobierno y de la dirigencia partidaria tradicional - a la que despectivamente denominaba "partidocracia"-, a la vez que profundizó su perspectiva sobre el aspecto refundacional que debería tener la "solución" a la crisis. La editorialización pareció fundarse sobre un diagnóstico que daba por concluido en los hechos al gobierno y al proceso político iniciado en 1973.

En esta línea interpretativa, el 17 de marzo, ante un atentado guerrillero cerca del Comando General del Ejército, que había afectado circunstancialmente a civiles ajenos a la acción, Clarín remarcaba que nadie estaba exento de las consecuencias del "terrorismo" y que 
El diario Clarín y la cuestión de la "lucha antisubversiva" en el golpe militar...

no cabían dudas sobre que la Argentina estaba "en guerra". De allí que no debían existir vacilaciones para combatir a la "subversión" "con las armas que la República ha depositado en sus Fuerzas Armadas". La "extinción" de la violencia era el prerrequisito para superar la crisis nacional. Frente a lo que avizoraba como el deslizamiento de la Argentina "sin pausa hacia abismos más profundos", concluía en tono catastrofista y perentorio: "Es hora pues de detener la caída" (Clarin, 17/3/1976).

\section{Golpe de Estado y dictadura: "erradicar la subversión" con el monopolio de la fuerza y rechazar la "intromisión" internacional en la cuestión derechos humanos}

Luego del golpe del 24 de marzo, considerado un "final inevitable" por Clarín debido a la inacción tanto del gobierno como de los principales actores políticos e institucionales de la República (clase política, dirigentes gremiales, Parlamento), la línea editorial ofreció lo que hemos denominado como un "consenso expectante" hacia el gobierno militar, apoyando la restauración del "orden", la "lucha antisubversiva" y destacando la figura "moderada" del nuevo presidente Videla, pero demandando que se implementaran los planes desarrollistas (BORRELLI, 2010b). Vale destacar también que en la evaluación sobre las causas del golpe de Estado, el diario ubicó a la "violencia subversiva" como un factor más de desestabilización dentro del conjunto más amplio de la "crisis nacional", sin concebirlo como el elemento determinante que explicaba la intervención militar, que en todo caso aparecía vinculada a la imperiosa necesidad de resolver el "vacío de poder" y la crisis general del país y su dirigencia. Como se ha visto, esta posición se desprendía en parte de su visión por la cual la "subversión" era parte de un "conflicto global" más amplio vinculado con la persistencia de un orden económico subdesarrollado.

Como es sabido, el mismo día del golpe de Estado las Fuerzas Armadas pusieron en marcha el sistema represivo luego conocido como terrorismo de Estado, de secuestro en centros clandestinos, tortura y posterior desaparición forzada de millares de militantes políticos, integrantes de las organizaciones político-armadas, gremialistas 
combativos, estudiantes, y otros sectores combativos. Uno de los elementos más relevantes de este sistema clandestino fue su ocultamiento por parte de las autoridades, para lo cual los diarios fueron funcionales al autocensurarse y no publicar informaciones al respecto que no provinieran de las fuentes oficiales (SABORIDO y BORRELLI, 2011) ${ }^{20}$.

Durante los dos primeros meses del gobierno militar, Clarín no dedicó un editorial exclusivo para tratar el tema de la "lucha antisubversiva" o algún otro aspecto vinculado solo con la represión, sino que hizo referencias tangenciales al tema en editoriales destinados a realizar una evaluación general del gobierno. Las preocupaciones centrales del diario en estos primeros meses tendrán como eje, con especial énfasis, la cuestión económica, la probable participación de civiles en el autodenominado "Proceso de Reorganización Nacional" y algunos aspectos vinculados a la gestión de la administración del nuevo gobierno militar. Sobre la cuestión "subversiva" y la represiva en general, podría sintetizarse que mantuvo una política editorial "reactiva" frente a ciertos acontecimientos, pero en ningún momento se privilegió como una cuestión a poner en la "agenda" de los temas ineludibles de la realidad nacional. En otras ocasiones directamente se optó por el silencio estratégico ${ }^{21}$ para no opinar sobre sucesos que afectaban directamente a la "imagen" del gobierno, y cuya exposición pondría en riesgo la política de autocensura que los empresarios de medios habían acordado con los militares a inicios de abril, así como las buenas relaciones que se procuraba mantener con el poder por razones de preservación comercial de las empresas de diarios.

De todas maneras, en esas primeras expresiones, Clarín fue diáfano al demandar con firmeza la "erradicación" de la "guerrilla" y el "terrorismo", aunque explicitó desde un principio su preocupación sobre que la represión se ejerciera con un Estado que "monopolizara" el uso de la fuerza. Así, frente a la publicidad de actos criminales que no podían serles imputados a ninguno de los "extremismos" de "derecha o izquierda" - según la fórmula con que se denominaba a estos sectores desde los diarios - y que indubitablemente ponían un manto de duda sobre la acción gubernamental, insistió que el Estado ejerciera con "responsabilidad" el monopolio de la fuerza que le era legítimo, demanda que a su vez iba acompañada del rechazo genérico de la "violencia" y de 
El diario Clarín y la cuestión de la "lucha antisubversiva" en el golpe militar...

una suerte de "victimización" del gobierno militar, que en esta hipótesis aparecía sobrepasado por la acción de "bandas irregulares" que se autoarrogaban la función de represión en forma ilegal (Clarín, 19/6/1976; 25/6/1976; 28/6/1976).

El primer editorial del matutino dedicado exclusivamente al aspecto represivo, fue el 4 de junio de 1976 debido al secuestro y posterior asesinato en territorio argentino del general tercermundista y ex presidente boliviano Juan José Torres, que en 1971 había sido derrocado por el dictador Hugo Banzer y se había exiliado en la Argentina ${ }^{22}$. Esta vez sin dilaciones ni silencios estratégicos, Clarín se pronunció sobre el asesinato el día posterior al hallazgo del cadáver, bajo el título "El asesinato del general Torres" (Clarín, 4/6/1976). En primera medida, recordaba que días antes "dos políticos uruguayos" habían sido "brutalmente asesinados"23, y en ese marco el asesinato de Torres era un "nuevo testimonio de la anónima y salvaje actividad de grupos homicidas", referencia que remedaba la posición de los partidos políticos que en los primeros meses del régimen tendieron a diluir el peso de los acontecimientos represivos en referencias generales y amplias a la persistencia de la "violencia" (YANNUZZI, 1996, p. 115). Ambos hechos eran calificados como "lamentables" y "repudiables", sin embargo su preocupación central no parecía depositarse en la gravedad de los crímenes en sí mismo, sino en el perjuicio político que los autores buscaban infringirle al gobierno; al decir del diario se destacaba: "el claro designio provocador que anima a quienes planearon y ejecutaron tales actos". De forma tal que era inevitable concluir que "todo ha sido calculado para dificultar la acción del gobierno y comprometer su política de sereno y público castigo para los responsables de la corrupción y de la subversión que corroen las bases del ser nacional" (Clarín, 4/6/1976).

Pero tal vez lo más relevante de su opinión editorial era el conocimiento que Clarín dejaba entrever tenía sobre lo que ocurría en la interna militar en relación a la represión y cuáles eran los argumentos que el gobierno ofrecía sotto vocce a quienes tenían acceso a las cúpulas del poder:

[...] hay también quienes dentro de nuestras fronteras conspiran para imponer una intemperante y oscurantista noción 
de la convivencia, de acuerdo con la cual el gobierno es 'blando' cuando respeta los derechos humanos, condiciona el ejercicio de su fuerza al imperativo de la justicia o decide monopolizar la potestad de castigar a quienes lo merezcan.

Los que así piensan están también comprometidos en los hechos de violencia que hoy nos toca condenar. Ellos degradan la causa que pretenden defender, a la que no es posible asignar altos fines cuando éstos se persiguen con tan cobardes procedimientos; ellos desprestigian internacionalmente a la Argentina, que no puede pretender un lugar en el concierto de naciones civilizadas cuando tienen lugar en su territorio actos de barbarie inexcusable. Ellos, por fin, minan la acción de un gobierno empeñado en rescatar la decencia y perseguir la inmoralidad, de la cual estos crímenes son un destacado exponente (Clarín, 4/6/1976).

En primera medida, debe señalarse el rechazo explícito que este tipo de acontecimientos generó en el diario una vez que tomaron estado público; crímenes que se asociaba al tipo de violencia que había caracterizado la etapa previa a marzo de 1976, con la toma de estado público y la aparición del cadáver. Pero lejos de cualquier "desconocimiento" de lo que estaba ocurriendo en relación a la responsabilidad de las Fuerzas Armadas en la represión, el diario se mostraba bien informado en torno a las disputas internas sobre cómo debía ejercerse la represión, aunque ello fuera sugerido y no explicitado. El editorial realizaba una aprobación tácita a lo que por ese momento era el núcleo argumentativo que desplegaban Videla, su ministro del Interior Albano Harguindeguy, y otros funcionarios del gobierno en reuniones privadas a quienes tenían acceso a esos niveles y demandaban información o explicaciones verosímiles sobre personas desaparecidas: que la facción "dura" del Ejército y la Marina cometían "excesos" en la represión que no tenían la aprobación de los "moderados" del Ejército quienes, en cambio, querían frenar estos "desvíos" (también argumentaban que existían grupos que no respondían al gobierno y por tanto no podían ser controlados $)^{24}$. Esto funcionaba como un criterio legítimo para apoyar a ese 
El diario Clarín y la cuestión de la "lucha antisubversiva" en el golpe militar...

sector del gobierno que decía querer "corregir" la actitud de sus integrantes más díscolos y dotar así de mayor legitimidad su accionar.

Tanto el ocultamiento oficial del tipo de represión que se estaba concretando, como la imagen que persistía en la opinión pública sobre la existencia de un "extremismo" de "izquierda" y otro de "derecha", forjada en los años de violencia política previos al golpe, y la sensación de ubicuidad de la violencia política - que en muchos casos aparecía despersonalizada - ofrecían un margen para la verosimilitud de este tipo de versiones sobre los acontecimientos. A la vez, la "victimización" del gobierno militar que realizaba Clarín era un razonamiento funcional para que el matutino pudiera apoyar sin contradicciones tanto al proceso político que había abierto el "Proceso" como a figuras que se pretendían "moderadas", como el presidente de facto Videla (que, en estos primeros meses, intentó difundir un "perfil republicano" que fue legitimado por el diario, así como por amplias capas de la ciudadanía; NOVARO y PALERMO, 2003). De lo contrario, sugerir que el núcleo central del gobierno estaba involucrado con los hechos criminales que salían a la luz pública, no solo ubicaría al diario en un rol de oposición demasiado extremo que llevaría a una colisión inviable con las autoridades militares que recién accedían al poder estatal - y prometían ejercerlo por un largo periodo - dejándolo expuesto a eventuales represalias, sino que lo transformaría en cómplice de crímenes amparados por el gobierno debido al apoyo que el matutino le estaba brindando. Por lo tanto, esta suerte de "resguardo" interpretativo que se le otorgaba al gobierno militar era un recurso argumentativo que a su vez le permitía a Clarín resguardarse a sí mismo e indicarle al régimen que había que frenar a los sectores más "duros" dentro de sus filas para poner fin a este tipo de represión "descontrolada". Como máximo, en este razonamiento del diario, la responsabilidad del gobierno aparecía por su omisión, en tanto era su obligación “erradicar" la represión que tomaba cuerpo por fuera de cualquier ordenamiento jurídico (Clarin, 25/6/1976).

La necesidad de una represión legal monopolizada por el Estado y que restringiera los "excesos represivos" fue revalidado en otros editoriales. Días después del asesinato de Torres la opinión pública fue sacudida por el asesinato del jefe de la Policía Federal, 
general Cesáreo Cardozo, ocurrido el 17 de junio en un atentado de la organización Montoneros ${ }^{25}$. La acción se enmarcaba en una serie de grandes atentados que Montoneros realizó desde junio a noviembre de 1976 contra las fuerzas de seguridad y que tuvieron gran repercusión nacional e internacional (que incluyó asesinatos de empresarios y personal de las Fuerzas Armadas y de Seguridad). El diario catalogó el asesinato como un "cobarde atentado criminal" y un "infernal procedimiento" (Clarín, 19/6/1976). Nuevamente ubicó al gobierno como el garante de una represión controlada y moderada frente a las acciones de quienes buscaban radicalizarlo, al esbozar la hipótesis que la "acción subversiva" que había organizado el crimen tenía un plan deliberado de provocación "orquestado desde adentro y desde afuera para crear condiciones que lleven al gobierno a instaurar la represión indiscriminada" y colocar a la Nación al borde de su disolución. Contra ello era necesaria la "serenidad" de la parte más "sana" del país y la "firmeza". Esta debía traducirse en el establecimiento del monopolio de la fuerza por parte del Estado, es decir, "ejercido con responsabilidad y por personas autorizadas" y que haría falta para "soportar una tendenciosa campaña interesada en hacer aparecer a nuestro país y a su gobierno como irrespetuoso de los derechos humanos." Esa "nociva campaña" atribuía en forma irresponsable todo crimen a la "inspiración oficial", pasando por alto o subestimando la actividad de "bandas subversivas" (Clarín, 19/6/1976).

$\mathrm{Su}$ demanda sobre el control represivo estatal pareció concretarse en el corto plazo. El nuevo jefe de la Policía Federal que suplantaba a Cardozo, el general Arturo Corbetta, dirigió un mensaje al país al asumir el cargo donde aseguró que la Policía continuaría involucrada en la "lucha contra la subversión" bajo una "legítima y alta concentración de violencia centralizada, oficial, pública y controlada, aplicada con la decisión, pero también con la prudencia de los hombres que conocen sus deberes" (Clarín, 26/6/1976, p. 2). Las declaraciones se contradecían abiertamente con el entramado represivo clandestino que habían puesto en marcha las Fuerzas Armadas y la postura "legalista" del nuevo jefe policial se daba de bruces con el proyecto oficial. No duraría mucho en su cargo: renunció luego de un resonado atentado montonero a la 
El diario Clarín y la cuestión de la "lucha antisubversiva" en el golpe militar...

Superintendencia de Seguridad Federal, a inicios de julio de 1976. Por otra parte, también el mismo 25 de junio el Poder Ejecutivo modificaba el Código Penal, reimplantando la pena de muerte para ciertos delitos "subversivos", agravando penas y creando nuevas tipificaciones delictivas, como en el caso de los delitos económicos o para las penas de quienes facilitaran el "accionar subversivo" (la reforma entró en vigencia el 15 de julio de 1976, Clarín, 15/7/1976, p. 4). La pena de muerte formalmente nunca fue aplicada; el poder desaparecedor no apelaba a mecanismos legales. Pero este andamiaje legal procuraba mostrar a un gobierno "respetuoso" de los principios jurídicos ante la opinión pública.

Clarín, en su editorial "Precisiones sobre la violencia" (Clarín, 28/6/1976), aprobó las palabras del nuevo jefe de la Policía Federal y las reformas del Código Penal como un "claro y serio propósito de instaurar definitivamente el orden en nuestra convulsionada comunidad". La reforma del Código se justificaba porque el tipo de agresiones que sufría la sociedad habían desbordado toda previsión legal y ello amparaba la "necesidad de recurrir a una mayor severidad represiva". Según el diario, la reforma y las palabras del jefe policial definían la idea de "firmeza" que había mencionado Videla en sus discursos iniciales, y al mismo tiempo que llevaban tranquilidad a la "inmensa mayoría de la población ajena al delito y a la empresa subversiva, ponen en claro las reglas de juego aplicables a quienes se empeñan en destruir la sociedad argentina" (Clarín, 28/6/1976) ${ }^{26}$.

Como se ha comentado, esta posición era funcional a la lógica perversa del terrorismo de Estado en su articulación diurna/nocturna. El estado "diurno" no solo declamaba su apego republicano, sino que decretaba un entramado jurídico que en teoría aseguraba el control de las acciones represivas. Las conciencias de los civiles que seguían con expectativa la marcha del "Proceso" en este campo podían descansar con sosiego. El Estado demostraba públicamente que todo funcionaba bajo el imperio de la ley y de la ética, aquella que según su relato había sido transgredida una y otra vez durante la etapa del "descalabro peronista" y que los militares anunciaban que venían a restaurar. Si había sucesos que ocurrían por fuera de la ley, para el relato oficial se debía a bandas paraestatales que buscaban dañar al gobierno. Desde ya, la otra cara del estado "diurno" era la 
realidad "nocturna" y criminal del terrorismo de Estado y del autoritarismo: secuestros, torturas, asesinatos sumarios, desapariciones forzadas; y en otro nivel, cesantías de empleados públicos, exilios, persecución ideológica, censura y autocensura y, en definitiva, el uso arbitrario y fuera de la ley de todos los recursos estatales en función de un proyecto político reaccionario y de jaez refundacional.

La demanda de control represivo estatal de Clarín convivió con la exaltación de lo que consideró como "avances" de la "lucha antisubversiva"; así, luego que el Ejército diera el 19 de julio de 1976 con el lugar donde se escondía el máximo líder del PRT-ERP, Mario Roberto Santucho, quien fue muerto en el enfrentamiento (su cuerpo fue tomado por el Ejército y continúa desaparecido), Clarín se permitía conjeturar la próxima disolución de la guerrilla en el editorial "El principio del fin" (Clarín, 1/8/1976). Allí manifestaba un sólido apoyo a las Fuerzas Armadas en la "guerra contra la subversión", aunque reiteraba una moderada advertencia sobre la necesidad de reforzar el monopolio de la fuerza en el Estado.

En este contexto, la primera referencia editorial explícita sobre el tema "derechos humanos" fue realizada en el editorial del 16 de septiembre de 1976 titulado "Los derechos humanos", donde condenaba un reciente atentado guerrillero. Recordemos que hacia mediados de 1976 varios gobiernos habían reclamado informaciones al régimen sobre connacionales que habían sido secuestrados o desaparecidos en el país y sobre quienes no había mayor información. En muchos casos, la prensa se hizo eco de estos reclamos a través de las publicaciones de cables de agencias internacionales que mencionaban los reclamos (SCHINDEL, 2003, p. 151). Por su parte, el gobierno militar argentino, ante algunos acontecimientos criminales públicos, como el ya mencionado asesinato de Torres, había esbozado la idea de la existencia de una "campaña internacional" para desprestigiarlo al presentarlo como conculcador de los derechos humanos (Clarín, 3/6/1976, p. 3; FRANCO, 2002). En ese marco, Clarín en su editorial resaltaba el "análisis intencionadamente parcial" de "cierta prensa extranjera" que había elegido "como blanco a la Argentina con el pretexto de que sus autoridades no respetan los derechos humanos", entre otros argumentos que consideraban como un opinión injusta que recibía el país desde el exterior, ya que 
El diario Clarín y la cuestión de la "lucha antisubversiva" en el golpe militar...

no medía adecuadamente el tipo de "agresión subversiva" que había sufrido (Clarín, 16/9/1976). Un mes después, a raíz de las denuncias de exiliados ante un comité parlamentario estadounidense, el matutino se expresó nuevamente para desacreditar las denuncias que afluían desde otros países advirtiendo sobre la "intromisión" en los asuntos internos nacionales (Clarín, 6/10/1976).

El 24 de septiembre de 1976 se cumplieron seis meses del golpe de Estado, lo que se convirtió en el primer balance que el propio gobierno hizo frente a la opinión pública sobre su gestión. Clarín hizo lo propio, a través de la pluma de su flamante columnista político, Joaquín Morales Solá, quien en esta ocasión firmó la nota de opinión, que fue la única expresión del diario en este sentido ("Seis meses de Gobierno"; Clarín, 24/9/1976, p. 4). Allí justificaba el nacimiento del gobierno militar como respuesta a la crisis desatada por el "vacío de poder" y el peligro de "disolución" y "anarquía". Destacaba dos aspectos del gobierno: "los éxitos contra la subversión” y que las Fuerzas Armadas habían demostrado "cohesión" y no habían padecido crisis internas. Con respecto al primer punto, señalaba que desde la muerte de Santucho se había logrado reducir "a la mínima expresión” la capacidad de combate de la "sedición". Sin embargo, señalaba que "no sería objetivo si no se consigna, también, que en este lapso hubo violencia. El terrorismo de uno u otro lado produjo sanguinarios episodios que conmovieron a la opinión general del país", hechos entre los que se contaban la aparición de cadáveres desconocidos que nunca fueron identificados ${ }^{27}$. De todas formas, concedía que en los últimos tiempos habían menguado esos "signos de irracionalidad", aunque no habían "desaparecido totalmente". En este aspecto, retomando un discurso reciente de Videla, aseguraba que aún restaba resolver la "lucha contra la subversión" en los ámbitos político, social y económico que al fin y al cabo eran las condiciones que posibilitaban el "accionar subversivo". Un claro resumen de lo que había sido la posición institucional del diario, que rechazaba la violencia de los "extremismos" de todo signo político y resguardaba al gobierno al ubicarlo como "víctima" de los sectores que promovían una deriva represiva. 


\section{Consideraciones finales}

Como hemos analizado, tanto hacia el final del gobierno peronista como en el inicio de la dictadura, Clarín defendió en forma activa la legitimidad de la "lucha antisubversiva" encarada desde el Estado nacional en el marco de lo que se consideraba como una "guerra". Junto con ello demandó que éste no perdiera el monopolio de la fuerza represiva a mano de "bandas irregulares", más aun luego del golpe del 24 de marzo. En efecto, una vez que los militares se hicieron con el poder, consciente de la existencia de internas castrenses con respecto al tema represivo, el diario intentó mostrar al gobierno militar como una suerte de "víctima" de los sectores más "duros" de sus filas que, en esta hipótesis, promovían una deriva represiva sin miramientos legales.

Esta victimización del gobierno nacional sin duda solapaba la responsabilidad directa de éste sobre las acciones criminales que se estaban llevando adelante, pero a pesar de ello no debe dejar de valorarse que esta percepción de un gobierno "sobrepasado" por "bandas irregulares" en el accionar represivo fue sostenido por otros medios de prensa, así como también por dirigentes de toda índole, lo cual tendió a otorgarle cierta verosimilitud a este argumento, al menos en los primeros meses de la dictadura. Todo ello, téngase en cuenta, en un contexto donde para muchos ciudadanos aún parecían poco creíbles las versiones que en forma de rumores recorrían la sociedad sobre campos de concentración o desapariciones imprevistas; rumores que de todas formas convivían con hechos concretos de esta índole que ocurrían todos los días y que muchos ciudadanos comenzaban a conocer por experiencia directa o de terceros allegados. En este marco de ambigüedad, ocultamiento informativo y desorientación, debe valorase hasta qué punto el hecho que diarios como Clarín hayan ubicado al gobierno en este rol de "víctima" lograron legitimar transitoriamente en la opinión pública la idea sobre que éste no tenía una responsabilidad directa en la represión ilegal.

Por otra parte, un eje invariante en el análisis del matutino fue la concepción de la lucha militar contra la "subversión" como una faceta dentro de un conflicto global más abarcador, cuya resolución 
El diario Clarín y la cuestión de la "lucha antisubversiva" en el golpe militar...

radicaba, en última instancia, en dar respuesta a los problemas económicos del país con el impulso de la "solución desarrollista". Como se ha mencionado, esta perspectiva tendía a simplificar la complejidad de la realidad política argentina y de las motivaciones por las cuales amplias capas de la sociedad civil intervenían en la acción política directa, sobrevalorando las explicaciones de índole económica sobre otras que incluyeran elementos de tipo ideológico, político o cultural.

La demanda de una represión ordenada y legal, que sin duda fue otra invariante editorial en el periodo analizado, convivió con los términos extremos, grandilocuentes y catastrofistas con los que el diario se refirió a la posible "disolución de la nación" o a la necesidad de "erradicar a la subversión", y, en términos generales, al uso de una fraseología característica de la época que otorgó una clara legitimidad para las "soluciones represivas" extremas y radicalizadas.

Asimismo, ya en dictadura, cuando las sospechas sobre la violación de los derechos humanos provinieron del exterior, el matutino reforzó su alineamiento con el gobierno militar al defender la "lucha antisubversiva" y al denunciar esos señalamientos como "intromisiones" en los asuntos internos que debían ser rechazadas, debido en su perspectiva tanto a que los asuntos internos del país debían resolverse sin intervenciones extranjeras, como al supuesto desconocimiento de la situación excepcional por la que había atravesado el país y que había justificado la aplicación de medidas drásticas en la "lucha contra la subversión".

\section{THE NEWSPAPER CLARIN AND THE ISSUE OF "WAR AGAINST SUBVERSION" IN THE 1976 MILITARY COUP IN ARGENTINA}

Abstract: This article analyzes the arguments Argentina's Clarin newspaper's publisher regarding his defense of the "war against subversion" during the last months of the Peronist government of Isabel Peron in 1975 and early 1976, finalized after the coup of 24 March of that year. In particular, we inquire in their positions since October 1975, when the Peronist government ordered the military intervention in the "war against subversion" throughout the country, until September 1976 upon completion of the first half of the coup, when the morning will produce a report on the new military government.

Keywords: Argentina's military dictatorship. Coup in 1976. Clarin, Argentina press. "War against subversion". 


\section{Marcelo Borrelli}

\section{Notas}

${ }^{1}$ Este artículo ha sido parte de la investigación del autor para las tesis de finalización de la Maestría en Comunicación y Cultura (UBA) y el Doctorado en Ciencias Sociales (UBA), defendidas en 2008 y 2011, respectivamente. Aspectos preliminares de este trabajo han sido discutidos en el congreso REDCOM-2012. El autor desea agradecer especialmente el apoyo del Proyecto UBACyT 20020100100608 "Del juicio al indulto: derechos humanos y memoria de la dictadura en la gran prensa nacional (1983-1990)", dirigido por Jorge Saborido, y del CONICET, institución a la que pertenece como Investigador Asistente.

${ }^{2}$ Con una tirada promedio de 360.000 ejemplares diarios; por su parte, La Razón y Crónica llegaban a 500.000 sumando todas sus ediciones.

${ }^{3}$ Debido al apellido del ministro de Economía que impulsó las medidas, Celestino Rodrigo. El "Rodrigazo" incluyó una serie de medidas económicas de ajuste ortodoxo, como un gran aumento de tarifas y combustibles por sobre el aumento de salarios y una megadevaluación de la moneda nacional.

${ }^{4}$ El MID era integrante del Frente Justicialista de Liberación (FREJULI) que había ganado las elecciones del 11 de marzo de 1973 (un frente de partidos que lideraba el peronismo y se completaba con el desarrollismo y pequeños sectores desprendidos del socialismo, el radicalismo y los conservadores populares). El desarrollismo, pese a haber acompañado la plataforma electoral del 11 de marzo de 1973, no había suscripto los acuerdos programáticos inscriptos en la política económica de acuerdo entre los sectores del trabajo y del capital conocido como "Pacto Social", en junio de 1973, y consideraba que la política económica que había iniciado el ministro de Economía José Ber Gelbard perjudicaba los intereses empresariales y la capacidad productiva nacional. Desde inicios de 1975, el MID había ampliado su distanciamiento político del peronismo, que se debió no solo a motivos ideológicos, sino también políticos debido al reducido espacio que el justicialismo le había otorgado al MID dentro del FREJULI.

${ }^{5}$ Que exhorta al cumplimiento de reglas, advierte peligros, llama a la concordia (CASTELLI, 1991, p. 195-6).

${ }^{6}$ Recuérdese que luego de las elecciones del 11 de marzo de 1973 asumió como presidente el delegado de Perón Héctor J. Cámpora, quien solo estuvo en la presidencia desde el 25 de mayo al 13 de julio de 1973. Luego del breve intinerato de Raúl Lastiri, asumió finalmente la presidencia Juan Domingo Perón en octubre de 1973, luego de ganar las elecciones de septiembre de ese año. Perón fue sucedido en el cargo por su esposa, Isabel, luego de su fallecimiento, el 1 de julio de 1974.

${ }^{7}$ Durante 1960 el fenómeno insurreccional había asomado a la vida política argentina, pero fue hacia finales de esa década e inicios de la del '70 que se constituyeron las principales organizaciones político-armadas. Hacia mediados de los años 70 las organizaciones más importantes eran Montoneros - surgido 
en 1969, de inspiración católica y nacionalista que rápidamente se incluyó dentro del peronismo representando la "izquierda" del movimiento - y el Ejército Revolucionario del Pueblo (ERP), surgido en 1970 del trotskista Partido Revolucionario de los Trabajadores (PRT). Debido a que la bibliografía sobre el tema es amplia, recomendamos puntualmente para la historia de Montoneros el libro de Gillespie (2008), y para el PRT-ERP, el de Carnovale (2011).

${ }^{8}$ También se creaba el Consejo de Defensa Nacional, integrado por el ministro de Defensa y los tres comandantes con la asesoría del Estado Mayor Conjunto para "conducir la lucha contra todos los aspectos y acciones de la subversión". El andamiaje legal reforzaba la subordinación del poder político al militar en el orden represivo y también político.

9 También se determinaba que la Secretaría de Prensa y Difusión de la Presidencia, la Secretaría de Informaciones del Estado, la Policía Federal y el Servicio Penitenciario Nacional quedaban afectados al Consejo de Defensa a los fines de la "lucha contra la subversión" y que los gobiernos provinciales debían proveer todos los medios policiales y penitenciarios requeridos por el Consejo. La totalidad de la estructura represiva estatal quedaba bajo el mando real de las Fuerzas Armadas, que se amparaba en este marco legal para ampliar la militarización de la política.

${ }^{10}$ La Triple A fue impulsada por José López Rega, un ex cabo de la Policía Federal que ganó la confianza de Perón y de su esposa Isabel y fue ganando posiciones en el poder hasta ser ministro de Bienestar Social a partir de 1973. Desde esta posición impulsó clandestinamente acciones criminales, como atentados y asesinatos contra los sectores de la izquierda peronista, intelectuales y sectores de la izquierda combativa. En julio de 1975 se vio obligado a renunciar e irse del país por ser señalado por el sindicalismo peronista como el principal responsable del "Rodrigazo".

${ }^{11}$ La encíclica, del 26 de marzo de 1967, rechazaba las estructuras económicas que promovían la injusticia y hacía hincapié en el desarrollo como forma para superar las injusticias sociales dentro y entre los países.

${ }^{12}$ Sin embargo, es interesante destacar que la movilización política de amplios sectores de la civilidad y la posterior confluencia en las organizaciones políticasarmadas se dieron en el marco de la relativa expansión y bienestar económico de la segunda parte de la década del ' 60 y los primeros años de la década del '70. Y sus integrantes más activos pertenecían en muchos casos a las clases medias y también altas de los centros urbanos, más allá que la militancia política reconocía que una de sus causas era resolver la injusticia social que perjudicaba a los sectores más desprotegidos de la sociedad argentina.

${ }^{13}$ La Cámara de Diputados introdujo enmiendas al proyecto y fue remitido a la Cámara de Senadores para su reconsideración. Pero luego se interrumpieron las sesiones, se retiraron todos los proyectos y se clausuraron las sesiones extraordinarias con lo cual no pudo ser tratado. A inicios de 1976 el nuevo ministro 


\section{Marcelo Borrelli}

de Defensa, José Deheza, envió un nuevo proyecto que el Congreso no trataría porque sobrevino el golpe de Estado (GONZÁLEZ, 2007, p. 388-9).

${ }^{14}$ Esa percepción, que ponía al Estado en pie de igualdad con las organizaciones político-armadas, sería duradera en la sociedad argentina de los años posteriores y luego del fin de la dictadura. Tal vez la "teoría de los dos demonios" instaurada como relato oficial en la democracia postdictadura - que igualó la acción terrorista del Estado con las acciones armadas de la guerrilla - fue la mayor deudora del relato que hacía eje en la "guerra" de dos bandos, que la teoría resignificó como actores "externos" a una sociedad "rehén" e "inocente". Los militares, y sus apoyos civiles, atizaron esta versión de los hechos aupados sobre el registro colectivo que se había consolidado durante la lucha armada de fines de los años '60 y mitad de la década del '70.

${ }^{15}$ La extensión de la "lucha antisubversiva" a todo el país se efectivizó en los hechos hacia mediados de noviembre. Según datos de organismos defensores de los derechos humanos, las víctimas mortales de las Fuerzas Armadas y de Seguridad al amparo de los decretos de febrero y octubre de 1975 oscilaron entre un mínimo de 408 y un máximo de 473, entre desaparecidos y muertos cuyos cuerpos fueron encontrados (GARCÍA, 1995, p. 437-42). Las víctimas de los grupos paramilitares y parapoliciales de derecha en la represión general contra la izquierda durante 1975 habían sumado 923 víctimas, entre secuestrados desaparecidos y muertos cuyos cuerpos fueron encontrados. Según García (1995, p. 441), a las organizaciones de izquierda durante 1975 le correspondieron 179 víctimas fatales.

${ }^{16}$ Otros hechos relevantes durante este mes fueron la sublevación golpista del brigadier Orlando Capellini del 18 de diciembre, sofocada a poco de iniciarse pero que funcionó como preparación para el golpe del 24 de marzo, y el intento fallido de copamiento por parte del Ejército Revolucionario del Pueblo (ERP) del Batallón Depósito de Arsenales 601 Domingo Viejobueno, en Monte Chingolo, provincia de Buenos Aires, el 23 de diciembre, que dejó a la organización en una situación de extrema fragilidad. Clarín no se expidió editorialmente sobre este último episodio. Sobre la rebelión de Capellini - a la cual no condenó e interpretó como causa de la "crisis nacional" y la inoperancia del gobierno - concluyó que la crisis argentina iba llegando "a la etapa de su inevitable desenlace" (Clarín, 20/12/1975).

${ }^{17}$ En otro ejemplo de esta concepción, hacia fines de julio de 1976, el matutino elogiaba abiertamente al general Domingo Bussi, en ese momento gobernador de Tucumán y jefe de las fuerzas represivas en esa provincia, porque había citado a un empresario en cuya empresa se había constatado que los trabajadores desempeñaban tareas en "condiciones infrahumanas", para determinar "su responsabilidad" en las causas que promovían "la subversión". Clarín lo señalaba como una "actitud positiva" porque partía de un diagnóstico acertado sobre las causas de implantación del "fenómeno guerrillero". Para el diario, la decisión 
del ERP de situar el combate armado en esa zona era porque las condiciones de atraso social y económico conformaban un "caldo de cultivo propicio para ganar la adhesión de sus habitantes". En ese contexto, las condiciones locales de "frustración y estancamiento económico" facilitaban el accionar guerrillero (Clarin, 30/7/1976).

${ }^{18}$ Que alaba y exagera las bondades de determinadas políticas (CASTELLI, 1991, p. 195-6).

${ }^{19}$ Que diagnostica resultados de orden social y político (CASTELLI, 1991, p. 195-6).

${ }^{20}$ Autocensura que explícitamente Clarín aceptó en agosto de 1976: "La prensa argentina ha aceptado la necesidad de la vigencia de ciertas restricciones que resultan indispensables en los momentos difíciles que vive la Nación. Lo ha hecho porque es consciente de que ella debe también efectuar su aporte al combate contra la subversión. En tal sentido, la prensa nacional no tiene dificultades con un gobierno que persigue idénticos fines" (Clarín, 2/8/1976).

21 "Sería muy comprometedora para el diario si cada día tuviera que concretarse en una opinión sobre los hechos políticos del propio país: como todo actor del sistema político, el periódico necesita combinar sus silencios estratégicos con sus mensajes de apoyo, demanda o denuncia.” (BORRAT, 1989, p. 139).

${ }^{22} \mathrm{El}$ asesinato fue parte del Plan Cóndor, que permitió la coordinación y la colaboración en términos represivos de las dictaduras del Cono Sur (SIVAK, 1998).

${ }^{23}$ El 18 de de mayo habían sido secuestrados el ex diputado y ex senador Zelmar Michelini y el ex presidente de la Cámara de Diputados de Uruguay, Héctor Gutiérrez Ruiz. Michelini estaba exiliado hacía tres años en la Argentina porque los militares uruguayos lo acusaban de tener conexión con la organización guerrillera de ese país Tupamaros. Al momento de su secuestro trabajaba como redactor en el diario argentino La Opinión, que desde sus páginas encabezó una verdadera campaña por su aparición con vida. El 21 de mayo aparecieron los cuerpos de ambos acribillados junto con los de otros dos uruguayos, crimen que el gobierno intentó atribuirle al ERP. Años más tarde se sabría que había formado parte del Plan Cóndor.

${ }^{24}$ Robert Cox, director del diario de la comunidad británica en Argentina The Buenos Aires Herald, manifestó años más tarde que la persistencia que tuvo en ese momento el "mito" de la existencia de una posición "moderada" residía en el deseo de que tales argumentos fueran ciertos y que las desapariciones fueran transitorias (MOCHKOFSKY, 2004, p. 240). Entre otros, el director de La Opinión, Jacobo Timerman, fue una de las personalidades públicas influyentes que pensaba que había que reforzar la línea "moderada" del gobierno (MOCHKFOSKY, 2004, p. 241). Hasta la propia embajada de Estados Unidos en el país afirmaba que los dirigentes de los partidos políticos Unión Cívica Radical y Partido Justicialista (peronismo) no desconfiaban de la "mala fe" de Videla, sino de su incapacidad de controlar a la línea "dura" del Ejército (Clarín, Suplemento Zona, 22 de marzo de 1998). 


\section{Marcelo Borrelli}

${ }^{25} \mathrm{El}$ atentado tuvo gran repercusión en los medios además porque la bomba que atentó contra Cardozo fue ubicada debajo de su cama por una militante de Montoneros que era amiga de la hija del jefe policial.

${ }^{26}$ Clarín le otorgó una particular relevancia al discurso de Corbetta y a las reformas introducidas en el Código; no solo al ocuparse de ello en su espacio editorial, sino también en las crónicas políticas y en el comentario político dominical (Clarín, 27/6/1976 p. 2)

${ }^{27}$ El 20 de agosto las Fuerzas de Seguridad dinamitaron 30 cadáveres en la localidad de Fátima, cercana a Pilar, provincia de Buenos Aires, en lo que se conocerá como la "masacre de Fátima". Fue una represalia inmediata por el asesinato del general (r) Omar Actis el día anterior, quien había sido designado recientemente como presidente del Ente Autárquico Mundial 78, acción que se le había adjudicado a un comando montonero (sin embargo, se sospecha que su asesinato haya sido consecuencia de la interna militar) (LLONTO, 2005, p. 29).

\section{Referências:}

ACUÑA, Marcelo. De Frondizi a Alfonsin: la tradición política del radicalismo/1. Buenos Aires: CEAL, 1984.

ANDERSEN, Martin. Dossier secreto. El mito de la guerra sucia en la Argentina. Buenos Aires: Sudamericana, 2000.

BORRAT, Hector. El periódico, actor político. Barcelona: Gili, 1989

BORRELLI, Marcelo. Hacia el "final inevitable". El diario Clarín y la "caída" del gobierno de Isabel Perón (1975-1976). Tesis (Maestría en Comunicación y Cultura). Facultad de Ciencias Sociales, UBA, 2008. Mimeografado.

- El diario Clarín frente a la política económica de Martínez de Hoz. (19761981). Tesis (Doctorado en Ciencias Sociales). Facultad de Ciencias. Sociales, UBA, 2010a. Mimeografado.

"Escribiendo el epitafio: el diario Clarín en la antesala del golpe de Estado de 1976". Hologramática, v. 2, no 13, Lomas de Zamora: Facultad de Ciencias Sociales, Universidad Nacional de Lomas de Zamora, septiembre/noviembre, 2010b.

CARNOVALE, Vera. Los combatientes. Historia del PRT-ERP. Buenos Aires: Siglo XXI, 2011.

CASTELLI, Eugenio. Manual de periodismo. Buenos Aires: Plus Ultra, 1991.

DE RIZ, Liliana. (1986). Retorno y derrumbe. El último gobierno peronista. Buenos Aires: Hyspamerica, 1986. 
El diario Clarín y la cuestión de la "lucha antisubversiva" en el golpe militar...

FRANCO, Marina. 'La 'campaña antiargentina': la prensa, el discurso militar y la construcción de consenso. En Judith Casali de Babot y María Victoria Grillo (editores), Derecha, fascismo y antifascismo en Europa y Argentina. San Miguel de Tucumán: Universidad de Tucumán, 2002.

GARCÍA, Prudencio. El drama de la autonomía militar. Argentina bajo las dictaduras militares. Buenos Aires: Alianza, 1995.

GILLESPIE, Richard. Soldados de Perón. Historia critica sobre los Montoneros. Buenos Aires: Sudamericana, 2008.

GONZÁLEZ, Julio. Isabel Perón. Intimidades de un gobierno. Buenos Aires: El Ateneo, 2007.

ITZCOVITZ, Victoria. Estilo de gobierno y crisis politica (1973-1976). Buenos Aires: CEAL, 1985.

LLONTO, Pablo. La vergüenza de todos (el dedo en la llaga del Mundial 78). Buenos Aires: Ediciones Madres de Plaza de Mayo, 2003.

MACEYRA, Héctor. Las presidencias peronistas. Cámpora/Perón/Isabel. Buenos Aires: CEAL, 1983.

MOCHKOFSKY, Graciela. Timerman. El periodista que quiso se parte del poder (19231999). Buenos Aires: Debolsillo, 2004.

NOSIGLIA, Julio. El desarrollismo. Buenos Aires: CEAL, 1983.

NOVARO, Marcos; PALERMO, Vicente. La Dictadura Militar 1976/1983. Buenos Aires: Paidós, 2003.

SABORIDO, Jorge; BORRELLI, Marcelo. Voces y silencios. La prensa argentina y la dictadura militar (1976-1983). Buenos Aires: Eudeba, 2011.

SCHINDEL, Estela. Desaparición y sociedad. Una lectura de la prensa gráfica argentina (1975-1978). Tesis de doctorado, Universidad de Berlín, 2003. Mimeografado.

SIVAK, Martin. El asesinato de Juan José Torres. Banzer y el Mercosur de la muerte. Buenos Aires: Ediciones del pensamiento nacional, 1998.

VEZZETTI, Hugo. Pasado y presente. Guerra, dictadura y sociedad en la Argentina. Buenos Aires: Siglo XXI, 2002.

YANNUZZI, María. Politica y dictadura. Rosario: Fundación Ross, 1996.

Recebido em: 27/07/2012

Aprovado em: 25/09/2012 